\title{
BRASIL: EM BUSCA DE UM PAÍS MODERNO E INDUSTRIALIZADO ${ }^{1}$
}

\author{
Andrea Pacheco Pacífico ${ }^{2}$
}

\section{Introdução}

$\mathrm{O}$ presente artigo se funda na necessidade de apresentar um panorama da sociedade brasileira a partir dos anos 50, quando se buscou solucionar os problemas do desenvolvimento econômico e social brasileiro por intermédio do processo substitutivo de importações, até os dias atuais, momento em que o governo federal propõe a criação de um pacto social com todos os segmentos da sociedade, contemplando todas as classes sociais, ricas e pobres, fortes e fracas, dominantes e dominadas, inclusive a classe camponesa que ficou esquecida do pacto na década de 50.

Inicio este artigo buscando conceituar os termos modernidade e industrialização, mostrando a diferença entre o mundo europeu, o árabe, o chinês e o latino-americano e como se caracteriza a sociedade brasileira e a argentina face às noções de moderno e industrializado.

O tópico seguinte visa esclarecer o porquê da implementação da Política de Industrialização brasileira da segunda metade do século XX que, embora o intuito tenha sido a formação de um país moderno e independente, não alcançou o êxito a que se propôs, culminando em um endividamento dos setores públicos e privados não condizente com o crescimento brasileiro, ou seja, não houve uma modernização e uma industrialização do país e da sociedade compatível com os recursos recebidos. Desta forma, urge necessário se fazer uma auditoria da

\footnotetext{
${ }^{1}$ Este trabalho foi apresentado como nota parcial ao Curso de Doutorado no Centro de Pesquisa e Pós-Graduação para as Américas - CEPPAC da Universidade de Brasília - UnB, no segundo semestre de 2002, onde a autora esteve matriculada como aluna especial, na disciplina Política e Estado nas Américas, sob a orientação do Professor Benício Vieiro Schmidt

${ }^{2}$ Professora Mestre de Direito Internacional Público no UniCeub
}

Universitas - Relações Int., Brasília, v. 2, n.1, p. 13-29, jan./jun. 2004 
dívida externa brasileira para se chegar a uma modernidade independente dos países núcleos da Nova Ordem Mundial.

Por terceiro, mostro como os movimentos sociais surgiram, em decorrência da falta de confiança no Estado e também como o objetivo de diminuir os riscos da sociedade reflexiva recém-formada. Ademais, trago à baila de que forma foi e continua sendo útil, necessário e importante tais movimentos no Brasil, em prol da solução dos conflitos entre as classes, já que as lutas de classes se encontram estritamente ligadas aos problemas conjunturais de crescimento do Brasil, como bem afirma Cardoso ${ }^{3}$.

Ao final, apresento perspectivas positivas de desenvolvimento e de consolidação de um Brasil moderno e industrializado, especialmente em virtude do apoio governamental dado aos movimentos sociais.

Concluo recordando a imprescindibilidade do uso da linguagem na solução de conflitos de classes e especialmente no momento atual de transição por que passa a sociedade brasileira

\section{Modernidade versus Industrialização}

A modernidade é vista como um "estilo, costume de vida ou organização social que emergiram na Europa a partir do século XVII e que ulteriormente se tornaram mais ou menos mundiais em sua influência"4, o que a associa a um período de tempo e espaço geográfico definidos. Na verdade, o surgimento do capitalismo, na Europa do século XVII, trouxe um modernismo que se fortaleceu em um Estado-nação vigilante de todas as instituições e de todos os súditos, com um poder militar coercitivo, organizado e atuante e que se desenvolveu graças a um industrialismo que crescia de forma avassaladora.

Estas características de um Estado moderno giddeniano explicam porque $\mathrm{o}$ mundo chinês e $\mathrm{o}$ mundo árabe não são considerados sociedades modernas, embora tenhamos obtido destes

${ }^{3}$ CARDOSO, F. H. Dependência e Desenvolvimento na América Latina, $7^{\mathrm{a}}$ edição, RJ: Guanabara, 1973.

${ }^{4}$ GIDDENS, Anthony. As Conseqüências da Modernidade. SP: Unesp, 1991. p. 11.

Universitas - Relações Int., Brasília, v. 2, n.1, p. 13-29, jan./jun. 2004 
povos, entre outros, a escrita (Mesopotâmia e Fenícia), algumas técnicas de agricultura, de comércio e de navegação (Egito, Índia e Persia), a criação do papel, da bússola, da pólvora e os sistemas monetários e de pesos e medidas (China) ${ }^{5}$.

Muito embora o mundo chinês e o mundo árabe tenham nos deixado tais legados, a explicação de Giddens para o nascimento da modernidade na Europa é que "a sociologia não desenvolve conhecimento acumulativo da mesma maneira que, pode-se dizer, as ciências naturais", conhecimento e permaneceram em uma sociedade teocrática, onde a religião e o Estado, de tão intrinsecamente ligados, impedem-nas de alcançar o modernismo.

Quanto à América Latina, os Incas, os Astecas e os Maias também nos legaram técnicas de agricultura, irrigação, comércio, escrita pictórica e hieroglífica, além da astronomia, da astrologia e da matemática ${ }^{7}$. Tal fato mostra que, vista pelo prisma giddeniano, esta sociedade já nasceu moderna, ou melhor, não deidificada ou teocrática.

Atualmente, Castells defende que estejamos nos encaminhando à Sociedade de Informação ${ }^{8}$, ou seja, "a sociedade em rede, onde o Estado-nação teve seu poder abalado, o capitalismo foi reestruturado, a mão-de-obra foi individualizada e o emprego se tornou flexível e instável", trazendo mais riscos ao indivíduo e mais necessidade de se confiar nos sistemas abstratos de que trata Giddens, quais sejam, a confiança em fichas simbólicas, e.g. dinheiro, e em sistemas perito, e.g. advogados, arquitetos, contadores etc.

A necessidade de confiança em sistemas abstratos e sistemas perito nasceu com a globalização ${ }^{10}$, já que a sociedade moderna é inerentemente globalizante, possuindo Estados-nação com economias capitalistas de caráter mundial e ordem militar institucionalizada, além

${ }^{5}$ Almanaque Abril. SP: Abril, 2002. pp. 491-498.

${ }^{6}$ Ibiden. p. 24.

${ }^{7}$ Almanaque Abril. Ibiden.

${ }^{8}$ CASTELLS, Manuel. A Era da Informação: Economia, Sociedade e Cultura. Vol. 2: O Poder da Identidade. $3^{\text {a }}$ edição. SP: Paz e Terra, 1999.

${ }^{9}$ Ibiden. prefácio de Ruth Cardoso. p. 17.

${ }^{10}$ Definida por Giddens como sendo "a intensificação das relações sociais em escala mundial", op. Cit. p. 69.

Universitas - Relações Int., Brasília, v. 2, n.1, p. 13-29, jan./jun. 2004 
da prevalência da divisão internacional do trabalho. De fato, a modernidade globalizante transformou a sociedade tradicional familiar e agrária em uma sociedade moderna capitalista, industrial, totalitária e militarizada.

A sociedade moderna latino-americana herdou da sociedade moderna européia uma economia capitalista e uma ordem militar institucionalizada, embora os antagonismos ainda reinem neste espaço geográfico supra.

Os Estados Unidos da América, por exemplo, desde sua independência, deixaram de ser uma sociedade eminentemente agrária e se transformaram em uma sociedade moderna e industrializada. A confiança da sociedade no Estado decaiu menos do que na América Latina, embora a sociedade, no primeiro, tenha investido mais na confiança em sistemas abstratos e em sistemas peritos, abandonando parcialmente o Estado do Bem-estar social.

Já os Estados latino-americanos continuaram presos ao Estado do bem-estar social, dependendo do poder estatal a sua sobrevivência; embora o Brasil e a Argentina, dentre outros, tenham se beneficiado "da descentralização do poder e dos recursos nos anos 80 e 90, empreendendo uma série de reformas sociais e econômicas que vêm transformando a geografia institucional da América Latina"11.

Parece-me que vem se concretizando o dito popular que diz que "os governos nacionais na Era da Informação são muito pequenos para lidar com as forças globais, no entanto muito grandes para administrar as vidas das pessoas" "12. Assim, devido à dificuldade de administrar o novo surgido, os governos nacionais vêm descentralizando parte de seu poder em favor de instituições locais. Ademais, a falta de confiança no poder público perdura e a sociedade busca apoio e refúgio nas entidades privadas.

Com tudo isso, os Estados latino-americanos permaneceram subdesenvolvidos, ou seja, embora houvessem surgido setores industriais modernos, os setores agrários industrializados continuaram a prevalecer.

${ }^{11}$ CASTELLS. op. cit., p. 318.

${ }^{12}$ Ibiden. p. 319.

Universitas - Relações Int., Brasília, v. 2, n.1, p. 13-29, jan./jun. 2004 
Para Cardoso, as sociedades em desenvolvimento, como nos países latino-americanos, apresentam características peculiares em relação às outras sociedades, ou seja, "antes de se constituir a sociedade moderna, forma-se um padrão intermediário, híbrido, que caracteriza as sociedades em desenvolvimento"13. E acrescenta que "quando não, formam-se situações estanques entre um setor da sociedade que se moderniza e outros que permanecem arcaicos"14.

Brasil e Argentina, para citar apenas estes, são Estados que apresentam este antagonismo entre modernismo e tradicionalismo, com problemas conjunturais endêmicos, no tocante às possibilidades de um desenvolvimento econômico auto-suficiente e autônomo, bases de uma sociedade moderna e industrial.

Embora Brasil e Argentina tenham permanecido dependentes de grupos tradicionais internos e do sistema econômico capitalista norte-americano, a diferença entre ambos reside no fato de que a sociedade Argentina se modernizou em suas pautas de educação, saúde e incentivo à cultura, formando uma sociedade altamente educada e qualificada, enquanto que o Brasil seguiu com uma sociedade dominada pelos grupos tradicionalistas, sem modernizar suas pautas de educação e saúde.

As relações de dominação, peculiares às sociedades latinoamericanas em desenvolvimento, face às economias centrais que caracterizam tais sociedades não desenvolvidas dificultam o alcance de um modernismo industrial, já que se baseiam em um "tipo de um sistema econômico com predomínio do setor primário, forte concentração da renda, pouca diferenciação do sistema produtivo e, sobretudo, predomínio do mercado externo sobre o interno" ${ }^{\text {"15 }}$. Destarte, o Brasil, a Argentina e outros países latino-americanos resolveram alterar substancialmente sua política visando um desenvolvimento independente das economias e políticas centrais, especialmente dos EUA.

${ }^{13}$ CARDOSO. op. cit.. p. 17.

${ }^{14}$ Ibiden.

${ }^{15}$ Ibiden. p. 26

Universitas - Relações Int., Brasília, v. 2, n.1, p. 13-29, jan./jun. 2004 


\section{A Política de Industrialização Brasileira: Por um Brasil Moderno e Independente}

As esperanças brasileiras em um possível crescimento econômico se iniciaram nos anos 50 com o processo substitutivo de importações ${ }^{16}$, que "alcançou a fase de implantação de bens de capital e que, por suas características, parecia implicar a instauração de uma etapa nova e de natureza irreversível da industrialização brasileira, pois o efeito multiplicador da produção de equipamentos costuma acarretar um forte dinamismo econômico" ". Surgem os projetos nacionais do aço, as refinarias de petróleo, as centrais elétricas etc. É a fase de acentuação do papel do Estado, que deixa de ser um mero mediador da política de financiamento de investimentos estrangeiros no país e passa a atuar como defensor do mercado interno.

Nesta década, surge no Brasil o movimento populista como um movimento político onde os valores de massa prevalecem sobre os valores de classe ${ }^{18}$. O Estado firma um pacto com os latifundiários mais atrasados, com os agricultores que produziam para o mercado interno, com a classe média urbana, com os setores industriais já existentes e com a massa urbana ${ }^{19}$ no intuito de enfrentar e consolidar a política de industrialização substitutiva. É o momento de participação política dos grupos de classe média mais ampla.

Entretanto, os fatos atuais não nos confirmam o otimismo inicial do processo, já que desde os anos 60 o Brasil atravessa um período de estagnação relativa no qual continua submergida a sua

\footnotetext{
${ }^{16}$ Segundo Cardoso, "a fase chamada de industrialização substitutiva de importações caracterizou-se por um duplo movimento convergente: a expansão do setor privado da economia e, consequientemente, o fortalecimento da burguesia industrial e a criação de novas áreas de investimento, concentradas em torno da "indústria básica" e das obras de infra-estrutura, onde foi acentuada a participação estatal". Op. Cit., pp. 91-92.

${ }^{17}$ Idem. pp. 12-13.

${ }^{18}$ Idem. pp. 105-108.

${ }^{19}$ Lembrando que os setores camponeses foram excluídos da aliança desenvolvimentista desde tal época, o que talvez justifique o nascimento de movimentos sociais como o MST.
}

Universitas - Relações Int., Brasília, v. 2, n.1, p. 13-29, jan./jun. 2004 
economia, mesmo levando-se em conta a bolha de crescimento econômico ocorrida no início da década de 70.

Uma dificuldade clara foi devido a que este tipo de indústria "não permite facilmente a reconversão das indústrias ou sua eliminação nos períodos de crise" ${ }^{, 2}$, ao contrário da indústria de produção de bens de consumo.

O resultado para o Brasil, assim como para a maioria dos países latino-americanos, como a Argentina, foi um aumento na desigualdade de distribuição de renda e uma crescente participação de capitais estrangeiros na economia, impedindo assim a concretização do objetivo inicial do processo substitutivo das importações, qual seja, um desenvolvimento auto-suficiente e autônomo, como acima citado.

O Brasil, então, terminou por se consolidar como um país agrário industrializado, ao invés de um país industrial moderno ${ }^{21}$. Isto significa que vivemos em uma sociedade com um parque industrial ativo e relativamente competitivo, embora à sua sociedade falte uma política educacional e de saúde compatível com os investimentos recebidos. Por outro lado, a Argentina possui uma sociedade educada e culta, além de uma política de saúde moderna, embora seu parque industrial tenha se tornado obsoleto e fraco.

Os investimentos recebidos no Brasil, a partir da década de 60 , para a transformação da sociedade tradicional em uma sociedade moderna, industrial e independente não foram poucos e parece-me que possam ter sido suficientes para modernizar a sociedade brasileira. A pergunta reside em onde os recursos foram aplicados e no porquê de os resultados não terem se concretizados.

\subsection{A Situação da Dívida Externa Brasileira}

O fato comum na sociedade mundial é acontecer o crescimento de um país pela aplicação de recursos obtidos por meio da formação de dívidas externas, ao tempo em que os recursos recebidos são aplicados

${ }^{20}$ CARDOSO. op. cit.. p. 13.

${ }^{21}$ Embora ao Brasil não falte abundante oferta de mão-de-obra, disponibilidade de terras apropriáveis e considerável quantidade de produtos para desenvolver o setor exportador.

Universitas - Relações Int., Brasília, v. 2, n.1, p. 13-29, jan./jun. 2004 
em investimentos produtivos, tais como: modernização dos recursos humanos, do parque industrial, da saúde etc, ou seja, em busca de solucionar problemas de base da sociedade.

No Brasil, a história se passou um pouco diferente. Na década de $70^{22}$, a crise do petróleo interrompeu o longo ciclo de prosperidade mundial iniciado em 1950, embora tenha sido considerada a década do milagre econômico brasileiro, onde o crescimento da economia doméstica variou na média entre $7 \%$ e $12 \%$ ao ano. O Brasil, na verdade, adotou uma política gradualista de reforço às exportações e substituições das importações, com o intuito de captar poupança externa. Segundo Ceres Cerqueira ${ }^{23}$, de 1974 a 1982 ingressaram no Brasil recursos externos na ordem de 50 bilhões de dólares que, somando-se aos 30 bilhões de dólares que o Brasil perdeu devido à elevação do preço do petróleo, nossa dívida externa foi elevada para um total de 80 bilhões de dólares.

Em 1987, o Brasil decreta a moratória, ou seja, se recusa a pagar aos credores internacionais e perde credibilidade internacional, elevando o risco Brasil a um alto patamar.

Entre 1989 e 1990, a situação parece melhorar quando é levantada a hipótese de se fazer um controle das contas públicas, o que mexe com as classes dominantes da sociedade tradicional que até então imperam no país. O Governo do Presidente Cardoso recebe o país com a dívida externa na ordem de 180 bilhões de dólares e então decide assumir as dívidas dos estados-membros, dos municípios e das autarquias estatais, o que explica o fato de o montante da dívida externa brasileira alcançar a ordem de cerca de 230 bilhões de dólares, qual seja: quando a União assumiu a dívida daquelas entidades, o montante da dívida da União era de apenas cerca de 100 bilhões e o resto (dívida dos entes estatais) estava na ordem de 130 bilhões.

\footnotetext{
${ }^{22}$ Sob a ressalva de que a crise do petróleo em 1973 (consequiência do conflito árabeisraelense) provocou um choque que condicionou o comportamento da economia internacional de 1973 a 1978, aumentando o preço do petróleo em mais de 300\% entre outubro de 1973 e janeiro de 1974, conforme informe de Ceres Aires Cerqueira, in Dívida Externa Brasileira - Processo Negocial - 1983-1996. Brasília: BCB, 1997. p. 15.

${ }^{23}$ Op. Cit., p. 16.
}

Universitas - Relações Int., Brasília, v. 2, n.1, p. 13-29, jan./jun. 2004 
O acordo firmado entre o governo do Presidente Cardoso e os credores internacionais foi para o pagamento da dívida em trinta anos. Por outro lado, o acordo da União com os entes públicos foi para que houvesse um repasse mensal ${ }^{24}$ destes à União, na faixa de $15 \%$, para pagamento dos juros e capital da dívida externa, cuja negociação se deu por meio de C-Bonds com os credores internacionais.

Ademais, ainda persiste o seguinte problema: muito embora o Brasil tenha apresentado em 2002 um superávit na balança comercial de cerca de 13 bilhões de dólares, ainda precisou obter aproximadamente 11 bilhões de dólares de capital volátil de curto prazo e, normalmente, de custo mais caro, a fim de zerar seus compromissos financeiros internacionais em $2002^{25}$. O Banco Central do Brasil prevê que, para 2003, seja necessário captar apenas seis bilhões de dólares em capital volátil para complementar suas necessidades, a fim de satisfazer o acordo com os credores internacionais, tendo em vista que dos 38 bilhões previstos, 32 bilhões deverão ser cobertos pelo superávit da balança comercial, além dos investimentos externos que deverão ingressar no país durante este ano.

O que o governo brasileiro necessita é diminuir o risco Brasil, pois se o risco é baixo, a confiança dos investidores externos no país cresce e o valor dos títulos C-Bonds aumenta, o que facilita o alcance das metas impostas pelos ditos credores e o pagamento da dívida.

Ademais, deve ser revista e analisada a questão da aplicação dos recursos que entraram no país e foram os responsáveis pelo endividamento brasileiro. Embora nosso parque industrial tenha crescido e se modernizado, a sociedade permanece tradicionalmente ligada à indústria agrária.

O crescimento da economia brasileira a partir da segunda metade da década de 60 até os dias atuais não condiz com o montante do endividamento. Acredita-se que o montante da dívida que foi carreado para o país não tenha sido todo aplicado em investimentos

\footnotetext{
${ }^{24}$ Repasse proveniente de parte da receita obtida junto com o recebimento dos Fundos de Participação e outras formas de receita.

${ }^{25} \mathrm{O}$ saldo da balança comercial foi de cerca de 13 bilhões de dólares em dezembro de 2002 e o saldo dos investimentos externos foi de cerca de 14 bilhões, totalizando um superávit primário de cerca de 27 bilhões.
}

Universitas - Relações Int., Brasília, v. 2, n.1, p. 13-29, jan./jun. 2004 
produtivos, suspeitando-se que haja sido desviado para se concentrar em pequenos grupos da classe dominante e em paraísos fiscais. Por conta disso, há partidos políticos, como o PSTU, cuja bandeira de campanha se funda na defesa por uma auditoria da dívida externa, com o intuito de descobrir onde foram aplicados os recursos financeiros emprestados ao Brasil, especialmente depois que a União assumiu o total do contratado, como explicitado acima.

Voltando à crise na Argentina, esta também se endividou, mas pode-se claramente visualizar que os recursos externos adquiridos foram aplicados na formação de uma sociedade culta, com acesso à educação e à saúde, ao contrário do Brasil, onde a sociedade continua sem acesso público à educação e à saúde, além da falta de incentivo às artes em geral por estrita escassez de recursos.

A crise chegou a seu ápice e então surgem os movimentos sociais como consequiência da falta de confiança da sociedade no Estado.

\section{Os Movimentos Sociais de Expansão da Modernidade Brasileira}

Quanto aos movimentos sociais ${ }^{26}$, eles nasceram de movimentos trabalhistas do início da Revolução Industrial e do iluminismo, quando os trabalhadores lutaram por melhores salários e melhores condições de trabalho. Depois, surgiram os movimentos pacifistas contra, por exemplo, os testes nucleares e a ameaça de guerra nuclear (e a luta pelo desarmamento ${ }^{27}$ da sociedade moderna). A estes, aliaram-se os movimentos democráticos, contrários às ditaduras, principalmente, e eclodiram os movimentos ecológicos (e de

${ }^{26}$ Para melhor entendimento sobre o nascimento dos movimentos sociais, veja: GIDDENS. Op. Cit.. pp. 158-162.

${ }^{27}$ Em defesa do movimento em prol do desarmamento mundial, vale salientar a luta solitária do Embaixador brasileiro José Maurício Bustani, quando de sua gestão como diretor-geral da Organização para a Proscrição de Armas Químicas. Árduo defensor do multilateralismo, Bustani, que elevou de 87 para 145 o número de membros da OPAQ, foi destituído do cargo por pressão dos EUA (defensores do unilateralismo), no momento em que lutou pela integração à OPAQ de países como o Iraque, por exemplo.

Universitas - Relações Int., Brasília, v. 2, n.1, p. 13-29, jan./jun. 2004 
contracultura) nas últimas décadas, com várias ONGs trabalhando em defesa do meio ambiente.

Tais movimentos sociais nasceram da falta de segurança e de confiança no sistema local, que levou a uma idéia de perigo, com a consequiente necessidade de arriscar, especialmente de arriscar nos sistemas abstratos supracitados, onde o dinheiro é o maior exemplo.

No dizer de Ruth Cardoso ${ }^{28}$, "a globalização impõe padrões comuns, pois difunde uma mesma matriz produtiva, baseada na nova tecnologia que apaga distâncias, mas, por outro, propicia reações locais que nascem marcadas pela ampliação da comunicação e pelas novas práticas sociais". Desta forma, Castells coloca a questão da identidade como um núcleo resistente à homogeneização e que pode ser semente de mudanças sócio-culturais. Ademais, ele distingue três formas de identidade: a legitimadora (emanada das instituições dominantes), a de resistência (proveniente de atores sociais em posições discriminadas ou desvalorizadas) e a de projeto (produzidas por atores sociais com acesso a materiais culturais necessários a redefinirem suas posições na sociedade). A importância de tal classificação reside no fato de que a diversidade das manifestações buscará enquadrar cada uma destas em cada categoria de movimentos sociais, que o próprio Castells ${ }^{29}$ define como sendo "o que dizem ser (...), conforme definido por suas práticas, valores e discurso e relacionados aos processos sociais aos quais parecem estar associados".

$\mathrm{Na}$ verdade, em virtude da natural evolução social não existe movimento social bom ou mau, pois todos eles são sintomas da sociedade onde nascem e se propagam e causam impacto nas estruturas sociais, em graus de intensidade e resultados distintos, podendo ser revolucionários, conservadores, ambas as coisas ao mesmo tempo ou nenhuma delas ${ }^{30}$.

No passado, a sociedade era previsível, possuindo um sistema social hierárquico e com poucas possibilidades de mudanças. Por outro

${ }^{28}$ CASTELLS. Op. Cit.. prefácio. p. II.

${ }^{29}$ Op. Cit.. p. 94-95.

${ }^{30}$ Ibiden.

Universitas - Relações Int., Brasília, v. 2, n.1, p. 13-29, jan./jun. 2004 
lado, a sociedade atual ${ }^{31}$, ou melhor, aquela que não era conhecida até há pouco tempo, mas que se tornou global, é a sociedade onde não há estabilidades nem garantias para os indivíduos e onde a única opção para estes é a reflexividade, ou seja, o cidadão precisa possuir uma alta capacidade de reflexão e para tomar decisões autônomas e individuais.

Esta sociedade individualista e instável trouxe como consequiência o avanço de movimentos sociais e políticos, e.g, feminismo, ambientalismo, religiosismo e etnicidade, que se ligam em rede à globalização tecnológica, ao poder da identidade dos grupos em movimentos e às instituições estatais. Desta forma, compete ao sistema político e as instituições estatais assimilarem as reivindicações dos movimentos sociais, pacifistas ou não, reativos ou pró-ativos, e lidarem com tais movimentos, que, segundo Castells ${ }^{32}$ serão responsáveis, em grande parte, pelos moldes do futuro da sociedade do século XXI.

No Brasil, há vários movimentos sociais, geralmente pacifistas, tanto reativos como pró-ativos, emanados de identidades diversas. Um bom exemplo de movimento social reativo e anti-globalização é o Fórum Social Mundial, já legitimado pelo sistema político estatal e que, inclusive, no último encontro recebeu como orador o Presidente da República.

Outro exemplo é o Movimento Sem Terra - MST -, um movimento social nos moldes de movimento reativo, nem sempre pacifista, que busca a defesa da identidade de uma classe agrária que se intitula discriminada, desvalorizada e rechaçada, mas que também tem sua legitimidade reconhecida pelo Poder Público, reforçando o modelo democrático brasileiro de procurar sempre, por todos os meios pacíficos, evitar lutas de classes.

Por terceiro, há o exemplo da Igreja Católica no Brasil, que também tem tido um papel importante nos movimentos sociais próativos de fortalecimento do modelo familiar patriarcal, ou seja, baseado na autoridade/dominação do pater familia. A Igreja vem lutando em defesa da manutenção da instituição familiar, cuja

\footnotetext{
${ }^{31}$ A sociedade atual é aquela chamada por Giddens (op. cit.) de Sociedade de Risco e por Castells (op. cit.) de Sociedade da Informação.

${ }^{32}$ Op. Cit. p. 137
}

Universitas - Relações Int., Brasília, v. 2, n.1, p. 13-29, jan./jun. 2004 
dissolução altera substancialmente a estrutura emocional, financeira e mental dos indivíduos, contribuindo para uma involução do ser humano e da sociedade. Alguns exemplos são os seguintes: ECC Encontro de Casais em Cristo, TLC - Treinamento em Liderança Cristã e o Movimento Focolare Família.

Por fim, cito o exemplo dos movimentos feministas, pois embora a luta em defesa da família patriarcal tenha aumentado, estes movimentos também cresceram e o seu ponto base é a luta em defesa dos direitos da mulher. Já existe, inclusive, a Comissão de Defesa dos Direitos da Mulher, órgão federal ligado ao Ministério da Justiça e também em níveis estaduais e municipais. Além disso, as seccionais da Ordem dos Advogados do Brasil possuem em seus quadros as comissões de defesa dos direitos da mulher.

O que se depreende do acima exposto é que o enfraquecimento do modelo estatal tradicional, em virtude do fortalecimento do modelo estatal globalizado, capitalista, informatizado e militarizado, provocou uma crise social, que resultou no surgimento de uma sociedade de risco, reflexiva e ausente de confiança no poder público. Ipso facto, a sociedade, temerosa da perda de sua identidade, buscou, em seu próprio seio, meios de se fazer ouvir, representar, agir e sobreviver, criando os movimentos sociais reativos e/ou pró-ativos.

Diante destes fatos, fica clara a importância do modelo democrático brasileiro na defesa das diversas classes existentes em nossa sociedade, especialmente se levarmos em consideração que o sistema político e as instituições públicas brasileiras têm procurado sempre legitimar os movimentos sociais surgido em seu núcleo, utilizando-se das formas mais pacíficas possíveis e levando em conta o sistema mundial moderno atual.

\section{Perspectivas de um Brasil Moderno e Industrializado}

Ainda que a formação de uma sociedade brasileira democrática, moderna e industrializada apresente altos riscos, em virtude da Nova Ordem Mundial, as perspectivas de uma sociedade independente dos EUA, principalmente, ou de outros pólos de dominação política e econômica, são positivas.

Universitas - Relações Int., Brasília, v. 2, n.1, p. 13-29, jan./jun. 2004 
A tendência atual é que países em desenvolvimento, como o Brasil, a Argentina e outros países latino-americanos, com economias dependentes de países núcleos, se liguem a outros grupos, evitando ficar à mercê de um único Estado central, como se caracterizou em décadas anteriores a relação entre EUA e América latina.

Para tanto, as classes sociais, com o apoio do Governo Federal, têm redefinido seus papéis no contexto estrutural da situação política e econômica atual, estabelecendo bases de sustentação de poder com o fito de gerar uma dinâmica social e econômica positiva para o país.

No caso do Brasil, já se inicia um novo Governo com planos de melhor aplicação dos recursos e menos especulação, o que já é um bom começo, pois a especulação tão já enraizada e comum no sistema financeiro internacional, pelo menos quando feita com recursos públicos, tem trazido prejuízos incomensuráveis a países em desenvolvimento, como o Brasil e a Argentina.

As perspectivas sobre as possibilidades de desenvolvimento e de consolidação de um Brasil moderno e industrializado devem necessariamente passar pelo modo segundo o qual os grupos sociais locais conseguem estabelecer sua participação no processo produtivo e definir formas de controle institucional capazes de assegurar tal participação $^{33}$. E isto nada mais é do que o Pacto Social recentemente firmado entre o Poder Público Brasileiro, as entidades privadas e a sociedade em geral em prol do desenvolvimento e modernização do país. Ademais, tal Pacto se fixa na crença de um resultado positivo, ou seja, na transformação do Brasil em um país moderno e industrializado, nos moldes de países desenvolvidos ou de Primeiro Mundo.

De fato, lembra-nos Cardoso ${ }^{34}$ que o desenvolvimento é "resultado da interação de grupos e classes sociais que tem um modo de relações que lhes é próprio" e a situação atual de luta pelo crescimento brasileiro se apóia politicamente neste sistema de alianças intra e inter classes, distinto daquele que no passado assegurava o poder à hegemonia externa.

${ }^{33}$ Idem. p. 39.
${ }^{34}$ Idem. p. 22.

Universitas - Relações Int., Brasília, v. 2, n.1, p. 13-29, jan./jun. 2004 
Enfim, o curso provável dos acontecimentos futuros dependerá da ação coletiva entre o setor público e o privado "motivada por vontades políticas que tornem factível o que estruturalmente é apenas possível"35.

\section{Conclusão}

Um equilíbrio das forças é fundamental e imprescindível neste momento crucial de transição por que passam algumas economias latino-americanas, como a Argentina e a brasileira.

A solução encontrada pelo Brasil parece provável de trazer solução positiva, qual seja, o uso da comunicação no Pacto Social entre Governo e Sociedade com o intuito de alcançar o desenvolvimento harmonioso da sociedade brasileira. Neste caso, o uso da linguagem corrente, como meio para chegarmos a uma sociedade moderna, industrializada, livre do caos e detentora de uma relação de equilíbrio entre as classes seria o ideal. Como bem afirma Habermas ${ }^{36}$, "a ação social só se constitui na comunicação de linguagem corrente" e a "linguagem também é médium de dominação e de poder social, servindo à legitimação de relações de violência organizada". E acrescenta que "as revoluções nas condições de reprodução da vida material são, por sua vez, mediadas lingüisticamente".

A relação dialógica é a forma ideal de comunicação social, que apesar de todas as tensões e perturbações, sempre remete a um acordo, pelo qual ela existe ${ }^{37}$. E sempre foi e sempre será o meio mais eficaz de trazer a harmonia a um sistema caótico, desde que não seja um pseudodiálogo, mas, pelo contrário, uma intenção verdadeira das classes em prol da paz.

Parece-me que finalmente o Brasil decide aliar a teoria à prática e utilizar-se do Estado como mediador dos conflitos entre as classes intra e inter sociedade brasileira. Em primeiro lugar, o que quero dizer é que o Governo tem se imbuído do papel de mediador dos conflitos entre as classes existentes em nossa sociedade, sem excluir nenhuma

${ }^{35}$ CARDOSO. op. cit.. p. 143.

${ }^{36}$ HABERMAS, J. Sobre Verdade e Método de Gadamer [1967]. p. 21.

${ }^{37}$ HABERMAS, J. A Pretensão da Universalidade da Hermenêutica[1970]. p.68.

Universitas - Relações Int., Brasília, v. 2, n.1, p. 13-29, jan./jun. 2004 
delas, como ocorreu no passado e que provocou reações de conflito, resultando em maior dependência do país às forças externas. Em segundo lugar, o país tem assumido seu papel na Ordem Internacional, de líder latino-americano e porta-voz de vizinhos, irmãos e amigos menores e mais fracos política ou economicamente.

Estes são os primeiros passos para a aquisição do objetivo definido de modernizar e industrializar o país, melhorando, internamente, o nível geral da sociedade brasileira e, externamente, transformando-se em Estado-Núcleo da civilização latino-americana, que não possui ainda seu representante poderoso e central no jogo de poder mundial, como bem afirma Samuel Huntington ${ }^{38}$.

\section{Referências Bibliografias}

ALMANAQUE ABRIL 2002. São Paulo: Abril, 2002.

BANCO CENTRAL DO BRASIL. Disponível em http://www.bcb.gov.br.

BRENNER, Robert. Turbulencias en la Economia Mundial. 1998.

CARDOSO, Fernando Henrique. Dependência e Desenvolvimento na América Latina. $7^{\mathrm{a}}$ edição. RJ: Guanabara, 1973.

CASTELLS, Manuel. A Era da Informação: Economia, Sociedade e Cultura. Vol. 2: O Poder da Identidade. $3^{\text {a }}$ edição. SP: Paz e Terra, 1999.

CERQUEIRA, Ceres Aires. Dívida Externa Brasileira - Processo Negocial-1983-1996. Brasília: BCB, 1997.

GIDDENS, Anthony. As Conseqüências da Modernidade. SP: Unesp, 1991.

HABERMAS, Jürgen. Sobre Verdade e Método de Gadamer [1967], in Jürgen Habermas, Dialética e Hermenêutica: para a crítica da hermenêutica de Gadamer. Porto Alegre: L\&PM, pp. 13-25.

A Pretensão da Universalidade da Hermenêutica [1970], in Jürgen Habermas, Dialética e Hermenêutica: para a

38 HUNTINGTON, S. O Choque de Civilizações e a Recomposição da Ordem Mundial. SP: Objetiva. 1996. pp. 52-53.

Universitas - Relações Int., Brasília, v. 2, n.1, p. 13-29, jan./jun. 2004 
crítica da hermenêutica de Gadamer. Porto Alegre: L\&PM, pp. 26-72.

HUNTINGTON, Samuel P.. $O$ Choque de Civilizações $e$ a Recomposição da Ordem Mundial. SP: Objetiva, 1996.

INSTITUTO BRASILEIRO DE GEOGRAFIA E ESTATÍSTICA. Disponível em http://www.ibge.gov.br.

Universitas - Relações Int., Brasília, v. 2, n.1, p. 13-29, jan./jun. 2004 